\title{
A practical solution in delineating thin conducting structures and suppression problem in direct current resistivity sounding
}

\author{
Shashi Prakash Sharma* and Arkoprovo Biswas \\ Department of Geology and Geophysics, Indian Institute of Technology, Kharagpur 721 302, India. \\ ${ }^{*}$ Corresponding author. e-mail: spsharma@gg.iitkgp.ernet.in
}

In hard rock areas, conventional apparent resistivity measurement using Schlumberger resistivity sounding fails to detect thin conducting structures (2-D and 3-D fractures filled with groundwater and mineral aggregate) concealed at a large depth. In the present study, an attempt is made to way-out the detection problem of deep seated thin conducting layer. It is proposed to study the apparent conductance simultaneously with resistivity sounding to detect such conductive zones qualitatively. Apparent conductance is defined as the magnitude of current flowing in the subsurface for a unit applied voltage through current electrodes. Even though such measurement is of qualitative importance, it gives extremely valuable information for the presence of conductive zones at depth in challenging hard rock terrain. It has been observed that apparent conductance increases significantly when groundwater bearing fractures and conductive bodies are encountered in the subsurface. Field data from different locations are presented to demonstrate the efficacy of such measurement. The measurement assists to the conventional resistivity sounding for successful prediction of groundwater zones at large depth in different hard rock areas and is of enormous importance. The approach is also used for possible solution of suppression problem in the DC resistivity sounding when intermediate layer is not reflected in the resistivity sounding curve. Finally, the approach can be used together with resistivity sounding to solve many practical problems.

\section{Introduction}

Groundwater investigations in complex areas are being carried out by integrated geophysical approach (Monteiro Santos et al. 2006). Integrated geophysical studies using a combination of resistivity, very low frequency electromagnetic (VLF-EM), self-potential measurement in hard rock areas were presented by Bernard and Valla (1991) and Sharma and Baranwal (2005) for groundwater exploration. Joint application of direct current DC resistivity, electromagnetic (EM) and nuclear magnetic resonance (NMR) has been used by Goldman and Neubauer (1994) for groundwater investigation. Apostolopoulos (2008) proposed combined application of resistivity measurement using Schlumberger electrode configuration and dipole-dipole array for hydrogeological investigations. Presence of highly conducting bands in the form of minerals within the subsurface provides a good conductivity contrast between its deposit and the host (Legault et al. 2008; Nimeck and Koach 2008). Lithological

Keywords. Apparent conductance; resistivity sounding; apparent resistivity; groundwater investigation; mineral exploration; hard rocks; suppression problem. 
interface detection using DC resistivity and transient electromagnetic (TEM) is proposed by Dickinson et al. (2010). New experimental design for electrical survey has been proposed by Blome et al. (2011). Recent advances in geophysical survey design have been discussed by Maurer et al. (2010). Spatial focusing of electrical resistivity surveys considering geologic and hydrologic layering is discussed by Furman et al. (2007). A survey of current trends in near-surface electrical and electromagnetic methods is demonstrated by Auken et al. (2006).

Interpretation of resistivity data becomes challenging when the data is associated with inherent ambiguity such as equivalence and suppressions (Van Overmeeren 1989; Sharma and Kaikkonen 1999). Application of two or more geophysical methods requires more effort in data collection and interpretation. Since, electrical resistivity is widely used for groundwater and mineral investigation; attempts are being made to extract more meaningful information from independent D.C. resistivity measurements alone. This could minimize the use of different geophysical techniques and assists in the correct interpretation of resistivity sounding.

Improvement in groundwater and mineral investigation techniques is required for geologically complex areas that are becoming challenging dayby-day. Hard rock areas are more problematic than soft rock areas for groundwater availability. In hard rock area when resistivity increases gradually with depth then the presence of thin groundwater layer at greater depth may not be detected by the conventional resistivity measurements. Also, presence of thin mineralized zones or ore deposits in the form of a conducting layer may not be detected in resistivity sounding. This is due to the fact that apparent resistivity is the bulk resistivity of various layers and a thin layer in the form of fractures filled with groundwater or mineralized zone are not reflected in the resistivity sounding measurements. Detection of such structures is very important in hard rock areas. Once the detection of such layer is missed in the observed data, interpretation without considering appropriate number of layers will be misleading. Even though a conductive layer depicting groundwater or mineral aggregates within the subsurface could be present, misleading interpretation could guide for drilling at wrong locations. A fundamental question can be raised, is there any practical approach by which such layers can be detected in conventional resistivity sounding? In the present study, attempts have been made to detect thin layers at large depth in resistivity sounding measurement and efforts have been made to find the probable solution of the above problem.

\section{Electrical resistivity sounding}

In electrical resistivity sounding, current is injected into the ground with a pair of metallic electrodes and the potential difference is measured with another pair of non-polarizable electrodes. The ratio of potential difference and current flow yields the apparent resistance of the ground. This apparent resistance is multiplied by the geometrical factor of the array to get the apparent resistivity for a particular current electrode separation. Current electrode separation is gradually increased to allow current flow through deeper formation to depict variation in resistivity with depth.

During the survey, direct current resistivity meter was used which yields individual values of potential difference and current passing through the ground for an applied external voltage. External applied voltage was increased at 15 volt intervals up to a desired voltage to inject the current into the ground. Applied voltage was also increased when either the current flow in subsurface was less than $10 \mathrm{~mA}$ or potential difference was less than $10 \mathrm{mV}$. Applied voltage at various current electrode separations was also recorded together with current flow and potential difference. For uniformity, measured current flow $\left(I_{\mathrm{d}}\right.$ and $\left.I_{\mathrm{R}}\right)$ was normalized by the applied voltage $\left(V_{\text {app }}\right)$ and apparent conductance $\left(C_{\mathrm{A}}\right)$ is computed for various current electrode separations.

$$
C_{\mathrm{A}}=\frac{I_{\mathrm{d}}+I_{\mathrm{R}}}{2 V_{\mathrm{app}}}
$$

In the above equation, $I_{\mathrm{d}}$ and $I_{\mathrm{R}}$ are the current flow in direct and reverse directions, respectively. In principle, the apparent conductance is the inverse of net resistance offered by the subsurface at a particular current electrode separation and it has the unit $\mathrm{mS}$ (milli Siemens). It is emphasized that $C_{\mathrm{A}}$ may also depend on the contact resistance between the ground and current electrode. However, in hard rock areas, it is assumed that the contact resistance between the ground and current electrode is mostly uniform for different electrode separations.

With the above-mentioned assumption of uniform contact resistance in hard rock areas, $C_{\mathrm{A}}$ in the subsurface decreases with the increase of current electrode separation over homogeneous half-space. Increase in $C_{\mathrm{A}}$ at a particular current electrode separation reveals the presence of conducting structure encountered in the path of current flow. Further, similar magnitude of apparent conductance observed with the increase of current electrode spacing also indicates presence of conducting feature in the subsurface. A sudden increase in the $C_{\mathrm{A}}$ with the increase in current electrode separation is observed only if a conductive 
feature comes in the path of current flow. Therefore, increase in the magnitude of $C_{\mathrm{A}}$ in the subsurface indicates the presence of conductive features in the subsurface. We tried to study $C_{\mathrm{A}}$ in different areas

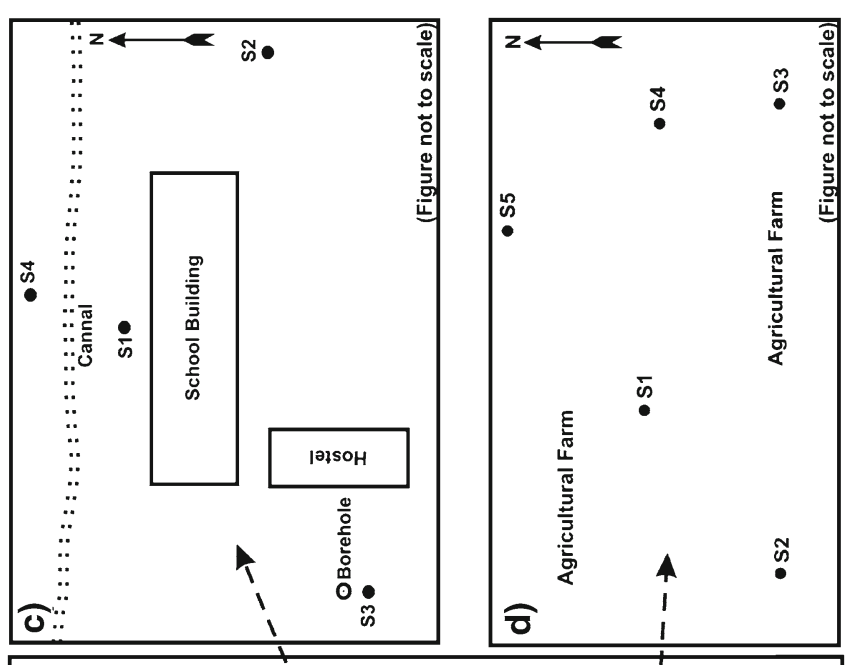

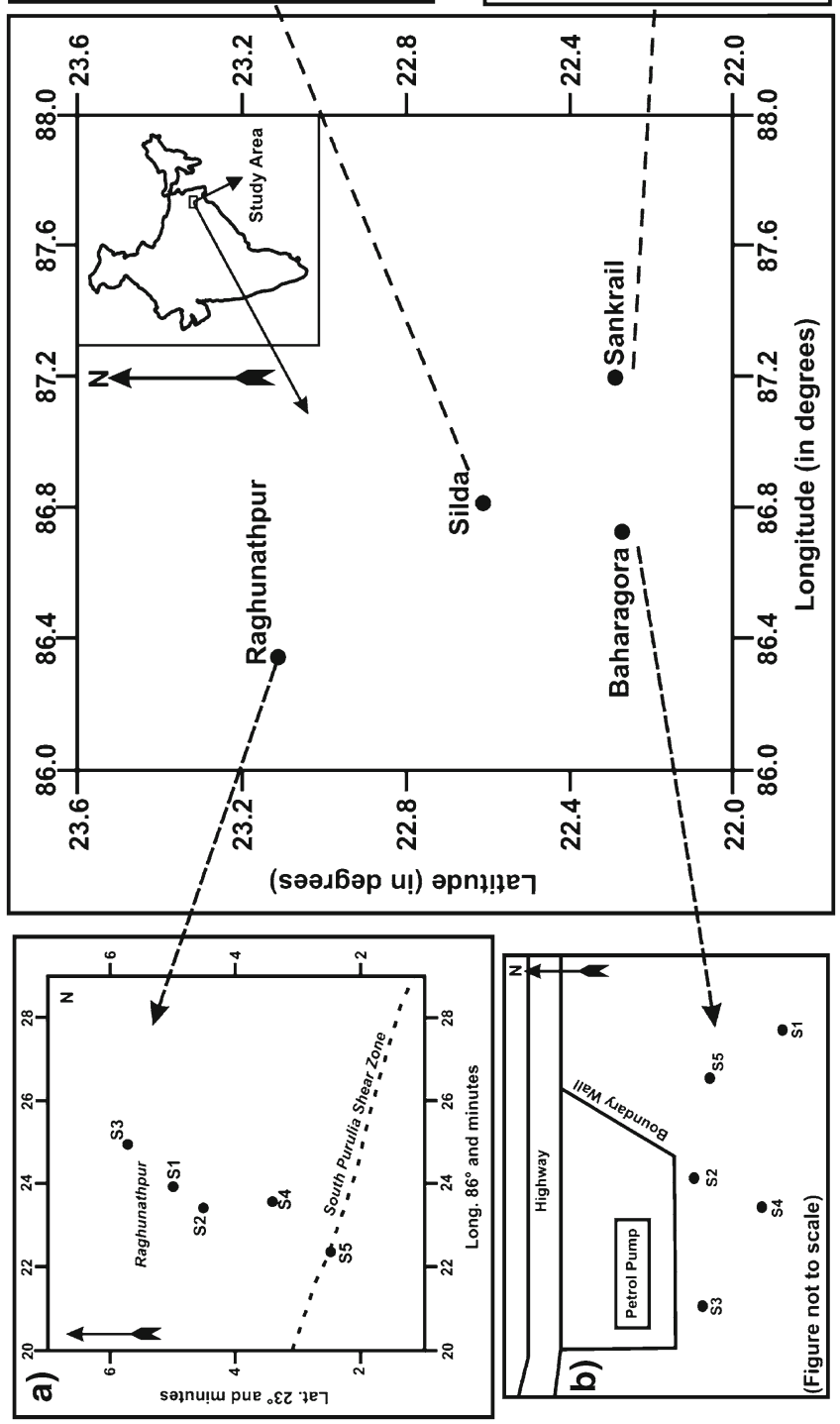
to learn its relationship with subsurface features or to get any additional information which might be helpful in qualitative or quantitative interpretation of conventional resistivity sounding data. To interpret the sounding data, some decisions about the number of layers and layer resistivities can also be taken on the basis of $C_{\mathrm{A}}$.

Theoretical development to compute apparent conductance over multi-layered structures between two current electrodes has not been attempted in geophysical literatures. This is due to presence of singularity (potential tending to infinite as distance decreases to zero) at current electrode positions. However, this potential in field measurements is equal to applied external voltage. Theoretically, when a conducting layer is present at depth then horizontal current density in that layer will increase. This increase in horizontal current density is qualitatively related with the amount of current flowing in the subsurface. However, precise theoretical magnitude of current flowing in the subsurface cannot be computed due to singularity occurring at current electrodes. Therefore, we have derived the expression of horizontal component of current density at various depths for varying current electrode separations. The derivation of horizontal current density is given in Appendix I. In Appendix I, it has been shown that horizontal current density increases when a thin conducting layer encounter at depth.

\section{Results}

Resistivity soundings have been carried out in four different parts of West Bengal and Jharkhand, India, for groundwater and mineral exploration purposes (figure 1). Current electrode separations were varied from 3 to $1000 \mathrm{~m}$ which was able to delineate structures at more than $250 \mathrm{~m}$ depths. The data was interpreted using 1-D very fast simulated annealing global optimization technique

Figure 1. Location map of the study area from the state of West Bengal and Jharkhand. (a) Location map of Raghunathpur and South Purulia Shear Zone with sounding locations. (b) Plan view map of petrol pump at Baharagora region with sounding locations (figure not to scale). (c) Plan view map of school at Silda region with sounding locations and borehole location (figure not to scale). (d) Plan view map of agricultural farm at Kalaikunda region near Sankrail and sounding locations (figure not to scale). 
(Sharma and Verma 2011). The results of sounding at different locations are discussed below.

\subsection{Silda (West Bengal)}

Silda is located at $22^{\circ} 36^{\prime} 25.5^{\prime \prime} \mathrm{N}$ and $86^{\circ} 48^{\prime} 59.36^{\prime \prime} \mathrm{E}$ in the state of West Bengal, India. This area is characterized by a thick surface clayey formation followed by laterite layer which continues up to a large depth. An ephemeral river Kansai is located at a distance of about $10 \mathrm{~km}$ east of the site. Shallow hand pumps (40-50 m deep) serve the purpose for drinking water in the area. Groundwater at this level corresponds to the contact between clay and lateritic basement. Since calcareous laterite has very poor permeability, finding any groundwater is problematic in the area. Investigation of possible thin sandy layers at depth is even more difficult because such layers are not reflected in the resistivity sounding curves. Field data from Silda near a government college is presented where there

Table 1. Interpreted model parameters for four soundings (S1-S4) from Silda region.

\begin{tabular}{lcccc}
\hline & $\mathrm{S} 1$ & $\mathrm{~S} 2$ & $\mathrm{~S} 3$ & $\mathrm{~S} 4$ \\
\hline$\rho_{1}(\Omega \mathrm{m})$ & 15.0 & 4.8 & 50.5 & 27.7 \\
$\rho_{2}(\Omega \mathrm{m})$ & 9923 & 24.6 & 12.3 & 62.6 \\
$\rho_{3}(\Omega \mathrm{m})$ & - & 9.89 & 9999 & 105 \\
$\rho_{4}(\Omega \mathrm{m})$ & - & 7406 & - & 9735 \\
$\mathrm{~h}_{1}(\mathrm{~m})$ & 34.3 & 0.4 & 1.0 & 7.9 \\
$\mathrm{~h}_{2}(\mathrm{~m})$ & - & 3.4 & 10.2 & 25.9 \\
$\mathrm{~h}_{3}(\mathrm{~m})$ & - & 24.5 & - & 46.6 \\
Misfit error & $1 \times 10^{-2}$ & $5 \times 10^{-3}$ & $4 \times 10^{-2}$ & $4 \times 10^{-3}$ \\
\hline
\end{tabular}

is scarcity of groundwater (figure 1a). Presence of thin groundwater layers has not been detected in resistivity sounding from this region. Hence, we tried to study $C_{\mathrm{A}}$ along with resistivity sounding data and tried to interpret the same. The results from $C_{\mathrm{A}}$ have been used combined with resistivity data to interpret the same and suggested drilling in those locations based on $C_{\mathrm{A}}$. Deep drilling has been successful in getting good amount of groundwater at suggested location. Table 1 presents the interpreted resistivity and thicknesses of various layers.

\subsubsection{Sounding 1 (S1)}

Resistivity sounding data (S1) presented in figure 2 is interpreted using a two-layered model. A thick clay layer on the top is followed by a massive resistive layer. The highly resistive layer is dry impervious laterite formation. Apparent resistivity data using conventional resistivity sounding fails to suggest the presence of groundwater at this location. A thick top layer with resistivity $15 \Omega \mathrm{m}$ and thickness $34.3 \mathrm{~m}$ does not suggest groundwater in it and second layer with resistivity $9923 \Omega \mathrm{m}$ is also too high to suggest any groundwater. It is rather difficult to decide whether to drill or not from such resistivity sounding data. This is a persistent problem in the study area as even 120-150 m deep tube wells produce very little groundwater and get dry at the beginning of the summer season. Attempts have been made to detect the groundwater zones in this highly resistive massive laterite layer. One could see from the ascending type apparent resistivity data (figure 2a) that it is not possible to detect the
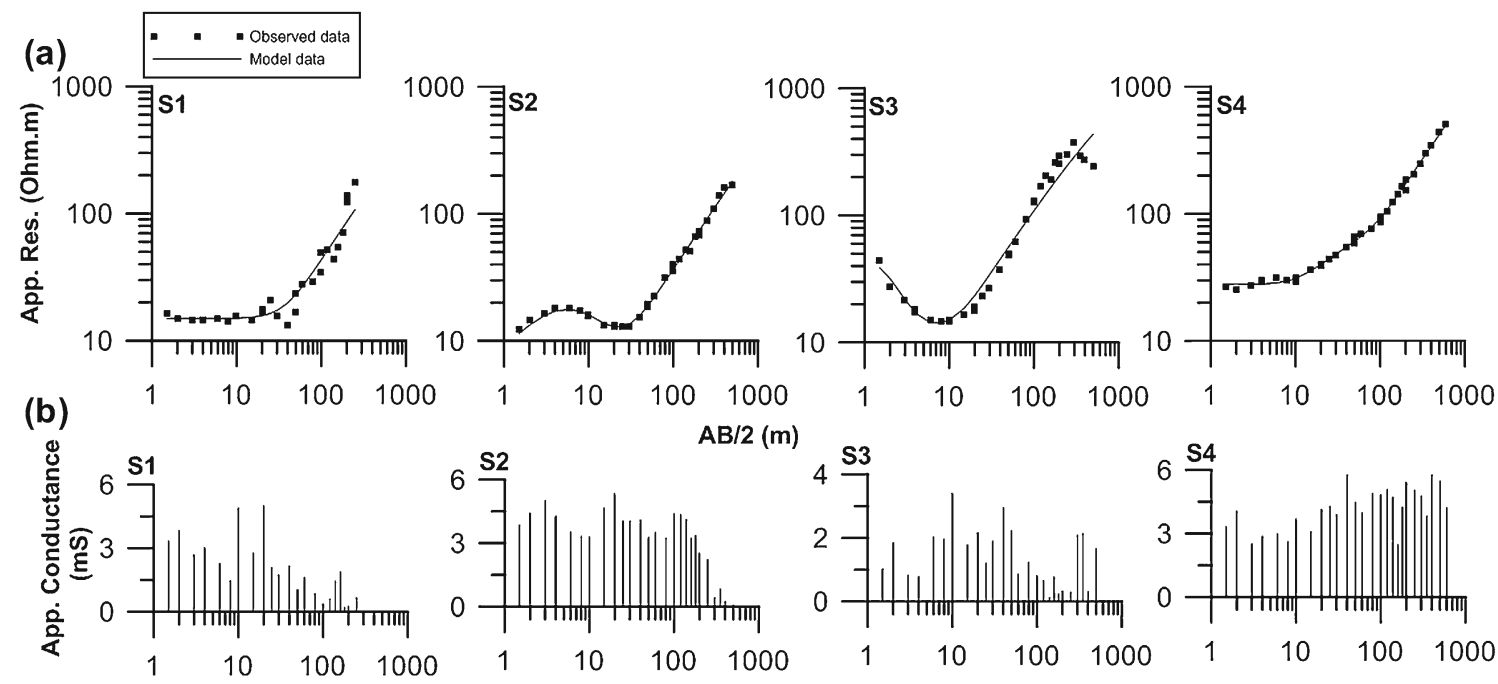

Figure 2. Interpretation of soundings (S1-S4) and variation of apparent conductance with current electrode separations (Silda). 
presence of a thin layer at large depth. However, $C_{\mathrm{A}}$ presented in figure $2(\mathrm{~b})$ reveals the different condition in the subsurface. There is an indication of increased current flow near the boundary of top clay and resistive laterite layer. It is important to mention that shallow hand pumps $(40 \mathrm{~m}$ deep) yield groundwater during the monsoon season and beginning of summer season (up to January). But these shallow hand pumps run dry in the beginning of summer. $C_{\mathrm{A}}$ has also been increased at 120-160 $\mathrm{m}$ values of half of the current electrode separation. However, its magnitude is not very large. It is important to mention that a $150 \mathrm{~m}$ deep tube well in the area produces a small amount of groundwater. This tube well yields groundwater up to the middle of summer and gets dry during the peak summer season (April-June). The groundwater problem is severe in the area for the peak summer season.

\subsubsection{Sounding 2 (S2)}

$\mathrm{S} 2$ is also performed in the same area and it depicts a four-layer resistivity sounding curve (figure 2a). The subsurface structure at depth is highly resistive laterite layer which has also been shown in the previous sounding. Apparent resistivity data shows a steep slope of $45^{\circ}$ depicting a massive resistive layer. It is very difficult to infer the presence of groundwater layer in this layer after looking at the sounding curve alone. However, $C_{\mathrm{A}}$ data shows that it has increased at $100 \mathrm{~m}$ current electrode separation (figure $2 \mathrm{~b}$ ). It is the same layer which was also observed in the previous sounding. $C_{\mathrm{A}}$ subsequently decreases and apparent resistivity keeps on increasing. This suggests that this sounding location may not yield good amount of groundwater. $C_{\mathrm{A}}$ data has very good correlation with the shallow hand pump data (increased value between 20 and $40 \mathrm{~m}$ ) and deep tube well (increased value 100$160 \mathrm{~m}$ ) that gets dry in peak summer. A slight increase in $C_{\mathrm{A}}$ at $350 \mathrm{~m}$ location is also observed which may depict the presence of fracture at large depth.

\subsubsection{Sounding 3 (S3)}

S3 and corresponding $C_{\mathrm{A}}$ data presented in figure 2(a) depict a 3-layer resistivity sounding curve. This sounding is also conducted in the same area at a different location. It is important to mention that the slope of this sounding curve is more than $45^{\circ}$, which suggests that horizontally layered earth model cannot fit the measured data. Figure 2(b) reveals that $C_{\mathrm{A}}$ has increased beyond $300 \mathrm{~m}$ current electrode separation. This clearly indicates the presence of conducting layer at larger depth. Low resistive layer corresponding to $10 \mathrm{~m}$ $\mathrm{AB} / 2$ value and increased $C_{\mathrm{A}}$ near $160 \mathrm{~m} \mathrm{AB} / 2$ value suggests the presence of small amount of groundwater. These two zones have very good correlation with the existing borehole information in the area. Comparison of apparent resistivity data of sounding 2 and 3 do not suggest a favourable zone for groundwater at a larger depth. However, similar comparison of $C_{\mathrm{A}}$ data for sounding 2 and 3 clearly indicates the suitability of the sounding 3 location for groundwater availability at large depth. A $250 \mathrm{~m}$ deep drilling was recommended on the basis of $C_{\mathrm{A}}$ data at the location of sounding 3. About $9.5 \mathrm{~m}$ thick sandy aquifer encountered at $201 \mathrm{~m}$ depth with sufficient amount of groundwater. A deep tube well is running successfully at this location throughout the year. Figure 3 shows the litholog of a $250 \mathrm{~m}$ deep tube well drilled at a location corresponding to S3. Groundwater was encountered at three depths in the borehole. First, at the interface between clay and laterite that forms the unconfined aquifer. Second and

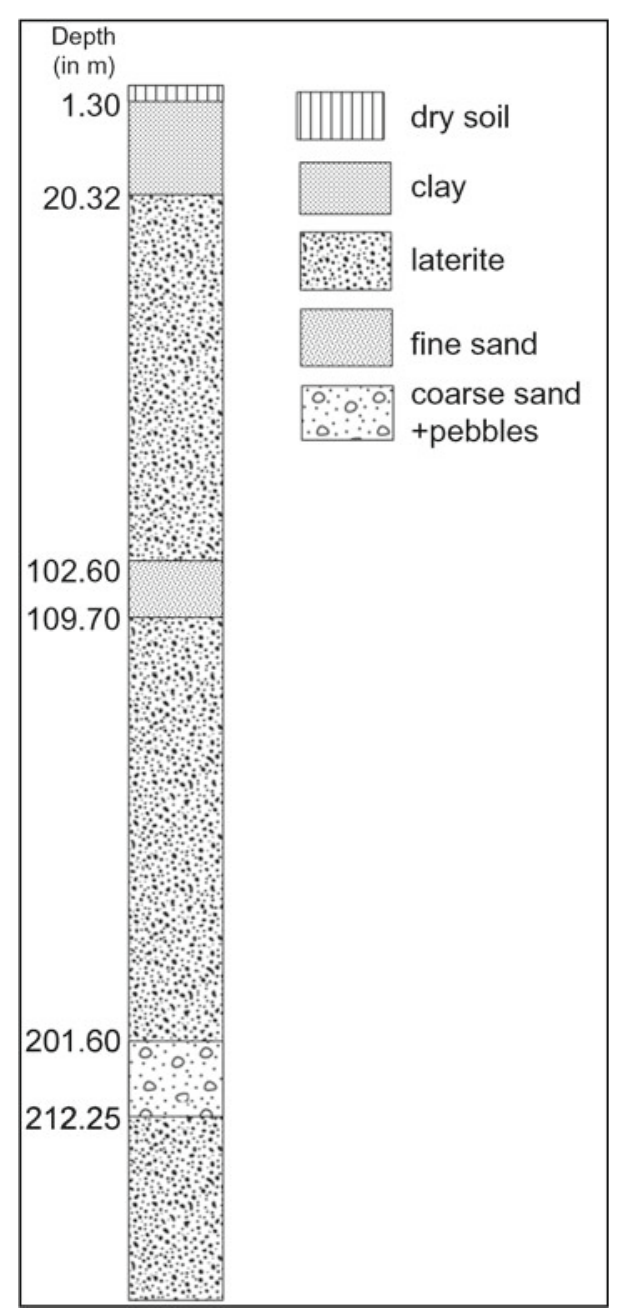

Figure 3. Litholog of $250 \mathrm{~m}$ deep borehole drilled at S3. 
third zones are in the form of fine sand and coarse sand with gravel, respectively. Clearly the second and third zones are not depicted in the resistivity sounding data; however, they are depicted in $C_{\mathrm{A}}$ data. Without the support of $C_{\mathrm{A}}$ data it would not have been possible to suggest drilling at this location. Interpretation of resistivity sounding data yields the actual depth. However, for a sounding curve with a slope more than $45^{\circ}$ (observed in this case for S1 and S3), only a qualitative assessment about depth could be made. Since current flow increases from $300-500 \mathrm{~m} \mathrm{AB} / 2$ at $\mathrm{S} 3$, assuming depth of investigation approximately $1 / 4$ th of current electrode separation drilling up to $250 \mathrm{~m}$ is justified to search in a water scarce area. The yield of the tube-well at S3 is 11,500 litre/hour. The yield of an existing old tube-well in the area which is $150 \mathrm{~m}$ deep and withdraws groundwater up to second zone is about 5000 litre/hour in rainy season. This yield decreases with time and old tube-well gets dry in summer. Since boreholes are drilled in the premises of Silda College, lithology and yields of the tube wells are provided by Silda College, Silda, Paschim Midnapore.

It is interesting to note that depth of the second layer in borehole at S3 is $20.3 \mathrm{~m}$, however, interpreted value shown in table 1 is $11.25 \mathrm{~m}$. The reason for this mismatch is poor fitting of resistivity sounding data with a slope more than $45^{\circ}$. We can see that model data do not fit the observed data for S3 in figure 2(a). To determine the accurate thickness we must consider the data up to $\mathrm{AB} / 2$ value where slope is up to $45^{\circ}$ only. Data up to $60 \mathrm{~m} \mathrm{AB} / 2$ values are interpreted using a 3layer model and exact thickness of the second layer which is shown in litholog was interpreted. Therefore, to get the actual depth one should interpret the data that are physically correct for the assumed layered model.

\subsubsection{Sounding 4 (S4)}

$\mathrm{S} 4$ and corresponding $C_{\mathrm{A}}$ data are presented in figure 2(a) depicting a 4-layer resistivity sounding curve. This is also performed in the same area and at a different location. The subsurface layer at greater depth is highly resistive. Apparent resistivity data show a steep slope of $45^{\circ}$ depicting a massive resistive layer. It is very difficult to infer the presence of groundwater layer in this layer after looking at the sounding curve alone. But the $C_{\mathrm{A}}$ data shows that the current flow in the subsurface significantly increases with depth. It is observed from the sounding that there is a constant high $C_{\mathrm{A}}$ till $500 \mathrm{~m} \mathrm{AB} / 2$ which suggest that groundwater may be present in the high resistive lateritic layer at depth.
There is a very good correlation in the $C_{\mathrm{A}}$ for the three soundings which were performed more than $300 \mathrm{~m}$ apart. Similarity in the observed $C_{\mathrm{A}}$ at various current electrode separations suggests that $C_{\mathrm{A}}$ data presented in figure 2(b) are associated with the subsurface structure rather than local conditions near the current electrode. Since, these soundings are conducted more than $300 \mathrm{~m}$ apart, therefore, $C_{\mathrm{A}}$ data depict the nature of subsurface structure. Similar observations regarding apparent conductance have also been made in different hard rock areas and the observations of $C_{\mathrm{A}}$ have qualitatively suggested the presence of groundwater bearing layers at depth that are not reflected in resistivity sounding data.

It is interesting to highlight that $C_{\mathrm{A}}$ may show increased value in the presence of moist ground surface. This can be seen for S4 where a consistence higher value of $C_{\mathrm{A}}$ has been observed. However, current flow is different for S1, S2 and S3. Hence, observing the apparent resistivity variation as well as $C_{\mathrm{A}}$ pattern one should decide the best location for successful drilling to get maximum amount of groundwater in an area. Therefore, drilling at S3 was recommended after observing these two parameters. Also in $\mathrm{S} 4$ where consistent same value of $C_{\mathrm{A}}$ is observed may yield groundwater. However, apparent resistivity data for S3 shows very favourable condition compared to apparent resistivity data for S4. Presence of moist ground near the current electrode may result in the slight increased current flow but significant increase in the current flow can be due to presence of fracture/layers filled with groundwater in water scarce areas. Since we deal with finding groundwater in challenging area; $C_{\mathrm{A}}$ assist in getting additional information in such regions. $C_{\mathrm{A}}$ should be studied together with apparent resistivity variation in selecting the best possible location. If a drilling fails at such location, then there is no point in drilling wild cat in the area to find groundwater. If groundwater is not present in the area, then some alternative arrangement should be made to supply water in such problematic area.

\subsection{Sankrail (West Bengal)}

The location is near Sankrail $\left(22^{\circ} 16^{\prime} 34.5^{\prime \prime} \mathrm{N}\right.$ and $87^{\circ} 7^{\prime} 5.62^{\prime \prime} \mathrm{E}$ ) in Paschim Midnapore district, West Bengal (figure 1b). Lithology in this area is similar to Silda. The main difference between Silda and Sankrail is that the surface clay at this location is very thin and massive laterite starts from very near surface. Subarnarekha River is located almost $16 \mathrm{~km}$ from this location. Resistivity soundings at Sankrail village is conducted on the request of PHED (Public Health and Engineering 

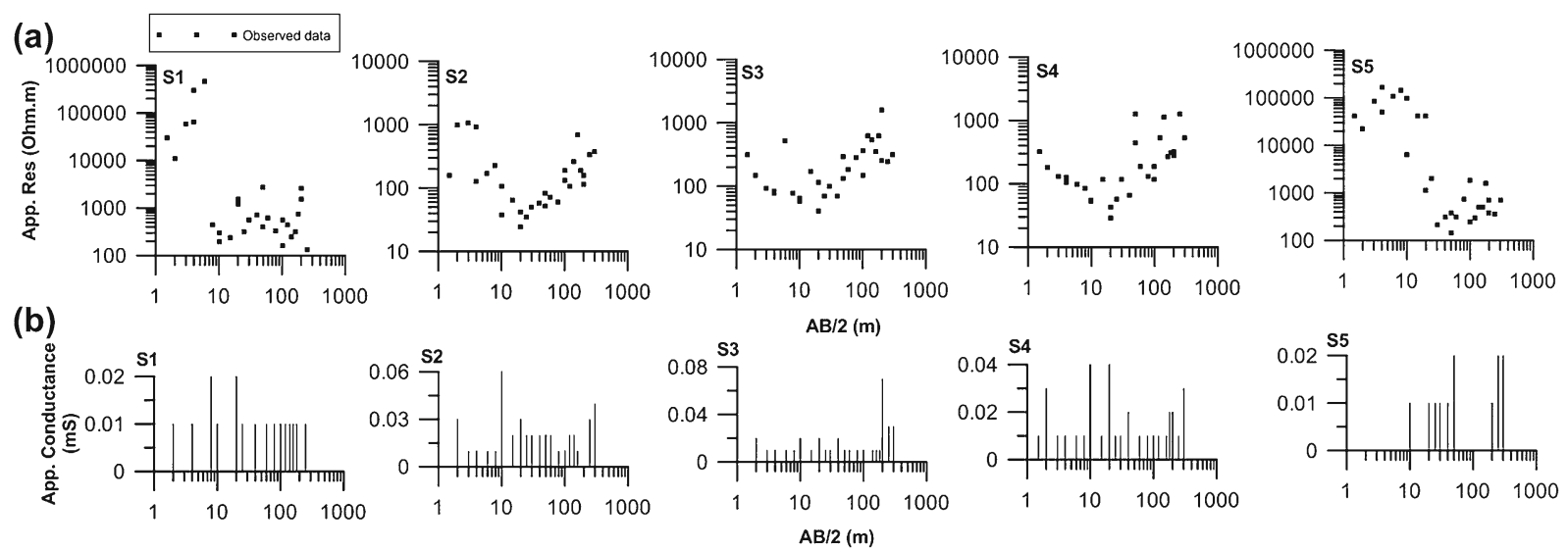

Figure 4. Soundings (S1-S5) and variation of apparent conductance with current electrode separations (Sankrail).

Department) after their failed drilling at a few location that does not serve their purpose as they encountered hard lateritic soil at a very shallow depth and they stopped drilling because of loss of drill bit. We tried to study the nature of the subsurface structure and lithology using resistivity sounding and found that the subsurface lithology is highly inhomogeneous and complex and we cannot interpret the resistivity data. Simultaneously, we studied $C_{\mathrm{A}}$ along with resistivity sounding and found better results from those data. It can be seen from figure 4 that all sounding data (S1-S5) behaves in similar manner. Therefore, scatter in the data is not the noise but it is due to complex heterogeneous nature of massive laterite present in the area. Finally, a location is suggested on the basis of $C_{\mathrm{A}}$ only and drilling was successful.

\subsubsection{Sounding 1 (S1)}

Initially, as a test case, this sounding is performed near a $50 \mathrm{~m}$ deep tube well that failed to produce any groundwater and loss of several drilling bits. The measured field data in S1 shows highly scattered data (figure 4a) and shows resistive inhomogeneous subsurface which cannot be interpreted with layered earth model assumption. However, the nature of the subsurface is highly complex. It is also evident from the fact that there is a sharp increase of $C_{\mathrm{A}}$ at a shallower depth $8 \mathrm{~m}$ and $20 \mathrm{~m}$ $\mathrm{AB} / 2$ values (figure $4 \mathrm{~b}$ ) and can be favourable for shallow aquifer whereas at greater depth there is a constant $C_{\mathrm{A}}$ which suggests a subsurface resistive structure. There is a shallow dug well (10 m deep) near the area. These dug wells overflow in rainy season and it goes dry after monsoon season. This observation can be seen from the apparent conductance. Even though apparent resistivity is scattered around $200 \Omega \mathrm{m}$, it cannot suggest this feature of the subsurface in which current flow has depicted. Since drilling has failed at this location and there is a need of water in the village, a deep source of groundwater at other location is investigated.

\subsubsection{Sounding 2 (S2)}

Measured field data in S2 also shows highly scattered apparent resistivity data (figure 4a) and depicts inhomogeneous subsurface which cannot be interpreted using layered earth model assumption. The nature of the subsurface structure is highly complex. There is an increase of $C_{\mathrm{A}}$ (figure $4 \mathrm{~b}$ ) at a shallower depth (10 and $20 \mathrm{~m}$ ) which is due to a low resistive zone. This zone is favourable for shallow aquifer whereas at greater depth (120-140 m and 250-300 $\mathrm{m} \mathrm{AB} / 2$ ), there is an increase in $C_{\mathrm{A}}$ and can be a favourable zone for deeper aquifer. Based on the nature of $C_{\mathrm{A}}$, drilling at this location is suggested up to $150 \mathrm{~m}$ depth. Groundwater bearing layers were encountered at two depths (84 and $130 \mathrm{~m}$ ) in the borehole.

Initially, drillers did not take responsibility to drill the massive laterite in this area. However, drilling up to $150 \mathrm{~m}$ was recommended by observing the consistence trend of current flow for larger current electrode separations. A thin (2-3 m) layer was encountered at $84 \mathrm{~m}$ depth that yielded very little amount of groundwater. This zone may correspond to a perched aquifer in laterite. Continuation of drilling was suggested and at $130 \mathrm{~m}$ depth about $5 \mathrm{~m}$ thick sandy water saturated layer was encountered. Drilling was stopped at $140 \mathrm{~m}$ depth after encountering the layer depicted in $C_{\mathrm{A}}$. The discharge of the well is 4000 litre/hour. This was sufficient to meet the requirement. The lithology and yield of the tube well are provided by the Public Health and Engineering (PHE) Department, Sankrial, Paschim Midnapore.

In a nutshell, without current flow pattern it would not have been possible to recommend drilling at this location. Even though it is unreliable to predict the exact depth but one can 
recommend the drilling up to $1 / 4$ th of current electrode separation for drilling if current flow indicate such an increase. For example, high current flow that has been detected $250-300 \mathrm{~m} \mathrm{AB} / 2$ at $\mathrm{S} 2$ corresponds to groundwater zone at $130 \mathrm{~m}$ depth.

\subsubsection{Sounding 3 (S3)}

The field data in S3 shows similarity to S2 (figure 4a). Since the nature of the subsurface is highly complex, it would not be feasible to interpret the data assuming layered earth model. But there is a sharp increase in $C_{\mathrm{A}}$ at $200 \mathrm{~m} \mathrm{AB} / 2$ (figure $4 \mathrm{~b}$ ), which can be a favourable zone for deeper aquifer.

\subsubsection{Sounding 4 (S4)}

The field data measured in $\mathrm{S} 4$ also shows similarity to S2 and S3 (figure 4a) and hence we cannot interpret the data with layered earth model assumption. From the sounding data, we can interpret that there is a low resistive zone at $10-20 \mathrm{~m} \mathrm{AB} / 2$ and

Table 2. Interpreted model parameters for three soundings (S1, $S_{4}$ and S5) from Baharagora region.

\begin{tabular}{lccc}
\hline & $\mathrm{S} 1$ & $\mathrm{~S} 4$ & $\mathrm{~S} 5$ \\
\hline$\rho_{1}(\Omega \mathrm{m})$ & 986 & 1297 & 658 \\
$\rho_{2}(\Omega \mathrm{m})$ & 21.6 & 24.7 & 70.6 \\
$\rho_{3}(\Omega \mathrm{m})$ & 130.3 & 100.7 & 54.8 \\
$\rho_{4}(\Omega \mathrm{m})$ & 15.6 & 17.5 & 19.4 \\
$\rho_{5}(\Omega \mathrm{m})$ & 8240 & 547.4 & 9531 \\
$\mathrm{~h}_{1}(\mathrm{~m})$ & 0.5 & 0.5 & 0.6 \\
$\mathrm{~h}_{2}(\mathrm{~m})$ & 0.8 & 0.5 & 4.8 \\
$\mathrm{~h}_{3}(\mathrm{~m})$ & 5.4 & 6.8 & 17.4 \\
$\mathrm{~h}_{4}(\mathrm{~m})$ & 15.7 & 15.9 & 19.7 \\
Misfit error & $3.3 \times 10^{-3}$ & $4.7 \times 10^{-3}$ & $8.9 \times 10^{-4}$ \\
\hline
\end{tabular}

is also a sharp increase in $C_{\mathrm{A}}$ at the same depth (figure 4b). Hence, we can say that there is a credible groundwater zone at the shallow depth. Also, at $300 \mathrm{~m} \mathrm{AB} / 2$, there is also a sharp increase in $C_{\mathrm{A}}$ but the subsurface is a highly resistive layer. It is due to the presence of groundwater in the fractured zones at a deeper depth.

\subsubsection{Sounding 5 (S5)}

The field data in S5 also shows a similar kind of variation as measured in previous soundings (figure 4a). From the sounding data, we can interpret that at $300 \mathrm{~m} \mathrm{AB} / 2$, there is also a sharp increase in $C_{\mathrm{A}}$ (figure $4 \mathrm{~b}$ ) but the subsurface is a highly resistive layer which is also in case of $\mathrm{S} 4$. It is also due to the presence of groundwater in the fractured zones at a deeper depth. There is an increase in $C_{\mathrm{A}}$ at $60 \mathrm{~m} \mathrm{AB} / 2$ value. It may be possible that there is some perched aquifer at this depth. It is interesting to note that perched aquifers in laterite are very common in this area. Presence of perched aquifer may be depicted by increase in current flow but that are not suitable to get continuous groundwater from them.

\subsection{Baharagora (Jharkhand)}

The survey location is near Baharagora $\left(22^{\circ} 16^{\prime} 57.03^{\prime \prime} \mathrm{N}\right.$ and $\left.86^{\circ} 42^{\prime} 55.66^{\prime \prime}\right)$ in East Singhbhum district of Jharkhand (figure 1c). Groundwater is a major problem in this area because of hard rocks and suitable aquifers are difficult to be delineated. Presence of groundwater in fractures of hard rock is well known and hence we tried to study resistivity sounding to delineate the deeper fracture aquifers. The sounding data alone may not give much information about the subsurface fractures; hence, we study the $C_{\mathrm{A}}$ along with
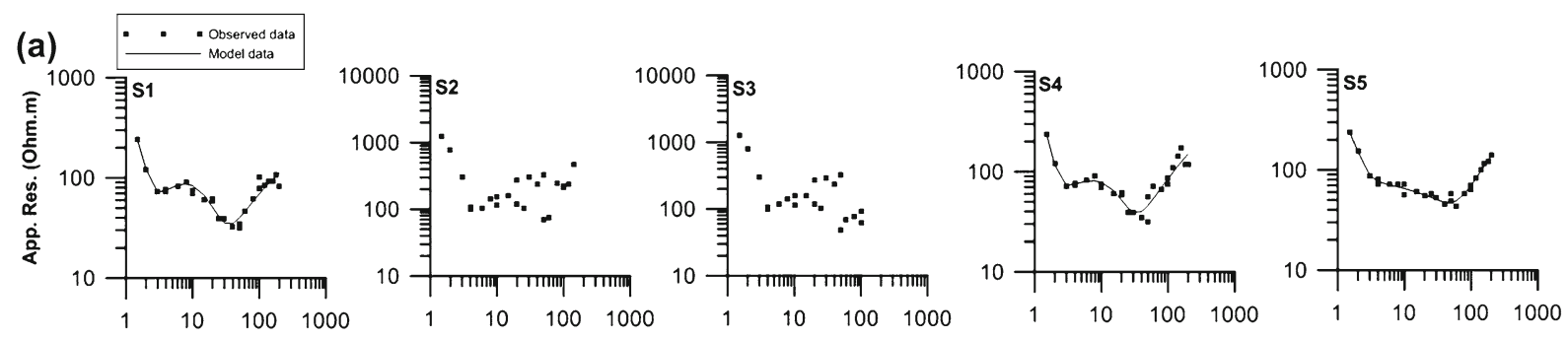

(b)
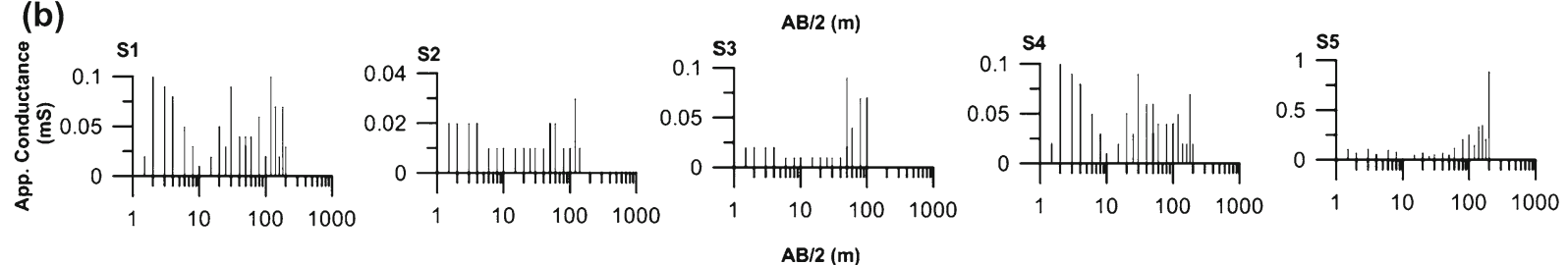

Figure 5. Interpretation of soundings (S1, S4 and S5) and variation of apparent conductance with current electrode separations (Baharagora). 
resistivity sounding which helps in delineating the fracture aquifers at deeper depth. Table 2 presents the interpreted resistivity and thicknesses of various layers.

\subsubsection{Sounding 1 (S1)}

Interpreted model parameter for $\mathrm{S} 1$ reveals a 5-layer structure (figure 5a). The first layer is top dry soil with thickness $0.54 \mathrm{~m}$ and resistivity of $987 \Omega \mathrm{m}$. Second layer is only $0.57 \mathrm{~m}$ thick and it is moist clay layer $(21.59 \Omega \mathrm{m})$. Third layer is dry laterite having thickness $5.39 \mathrm{~m}$ and resistivity of $130 \Omega \mathrm{m}$. Fourth layer is groundwater saturated layer $(15 \Omega \mathrm{m})$ with thickness $15.67 \mathrm{~m}$. This layer seems to be clay according to very low resistivity value; but it could also be saturated mica schist. Fifth layer is a massive hard rock formation that forms the basement in the area. Basement layer in the area is quartzite. Resistivity sounding data is not smooth that reveals the subsurface is inhomogeneous and complex. $C_{\mathrm{A}}$ increase at later electrode separation (figure $5 \mathrm{~b}$ ) indicates that water saturated layer may be present in the form of saturated mica schist in the basement rock. Increased $C_{\mathrm{A}}$ around $2-4 \mathrm{~m}$ and $20-30 \mathrm{~m} \mathrm{AB} / 2$ is correlated well with low resistive zone seen in apparent resistivity sounding curve. This means that this high value of $C_{\mathrm{A}}$ is associated with groundwater saturated zone even the apparent resistivity shows an increasing trend. The zones from 120-180 m AB/2 values indicate this possibility.

\subsubsection{Sounding 2 (S2)}

The measured field data shows a highly scattered data which cannot be interpreted with layered earth model and shows inhomogeneous subsurface (figure 5a). However, the nature of the subsurface is similar to the S1. So a broad conclusion could be drawn that 4th layer present at location S1 could also be encountered at this location in the borehole. This is also evident from the fact that there is a sharp increase of $C_{\mathrm{A}}$ similar to $\mathrm{S} 1$ and hence can be favourable for groundwater (figure 5b). Moreover, $C_{\mathrm{A}}$ values are smaller for this sounding compared to others. Therefore, drilling is not recommended at this location due to uncertain nature of the subsurface, smaller value of $C_{\mathrm{A}}$ compared to location $\mathrm{S} 1$ and finally better locations were depicted.

\subsubsection{Sounding 3 (S3)}

The field data in S3 is similar to $\mathrm{S} 2$ and cannot be interpreted assuming layered earth model (figure 5a). However, the nature of the subsurface is quiet similar to the $\mathrm{S} 2$. It is also evident from the fact that there is a sharp increase of $C_{\mathrm{A}}$ (figure $5 \mathrm{~b}$ ) similar to S1 and S2 at same current electrode spacing and hence can be favourable for groundwater. However, drilling is not recommended at this location due to uncertain nature of the subsurface. Moreover, if we have to select a site between S2 and S3 for drilling then S3 will be better than S2. This is due to smaller scatter in the apparent resistivity as well as lower magnitude of apparent resistivity and also due to large magnitude of $C_{\mathrm{A}}$ at S3 than S2.

\subsubsection{Sounding 4 (S4)}

Interpreted model parameter for $\mathrm{S} 4$ also depicts a five-layer structure (figure 5a) like S1. The first layer is top dry soil with thickness $0.49 \mathrm{~m}$ and resistivity of $1298 \Omega \mathrm{m}$. The second layer is only $0.52 \mathrm{~m}$ thick and it is moist clay layer $(25 \Omega \mathrm{m})$. The third layer is dry laterite having thickness $6.79 \mathrm{~m}$ and resistivity of $100 \Omega \mathrm{m}$. The fourth layer is groundwater saturated layer with thickness $15.53 \mathrm{~m}$. This layer seems to be saturated clay/saturated mica schist according to the very low resistivity. The fifth layer is a massive hard rock formation that forms the basement in the area. Fourth layer which forms the aquifer is relatively shallower and deep tube well may not successful at this location as well. Since S4 and S1 are similar, if we have to choose between $\mathrm{S} 1$ and $\mathrm{S} 4$ then $\mathrm{S} 1$ will be selected for the drilling. This is due to smaller value of apparent resistivity for larger current electrode separation at $\mathrm{S} 1$ in comparison to $\mathrm{S} 4$. Further, nature of $C_{\mathrm{A}}$ is also similar for these two soundings. However, larger $C_{\mathrm{A}}$ could be seen at larger current electrode separation for $\mathrm{S} 1$. Hence, $\mathrm{S} 1$ should be a better site than S4. This kind of comparison between the interpreted model parameter, measured data and $C_{\mathrm{A}}$ definitely guides to select the best site for drilling in any area.

\subsubsection{Sounding 5 (S5)}

Interpreted model parameter for S5 also shows a 5-layer structure (figure 5a). The first layer is top dry soil with thickness $0.59 \mathrm{~m}$ and resistivity of $658 \Omega \mathrm{m}$. Second layer is only $4.77 \mathrm{~m}$ thick and relatively moist soil only $(70 \Omega \mathrm{m})$. Third layer is further moist layer having thickness $17.43 \mathrm{~m}$. Fourth layer is groundwater saturated layer with thickness $19.86 \mathrm{~m}$. This layer again could be saturated clay/saturated mica schist according to the very low resistivity. Fifth layer is a massive hard rock formation that forms the basement in the area. Geologically the basement layer is quartzite. Resistivity sounding data for this sounding is relatively smooth so this location will be relatively better than other soundings. $C_{\mathrm{A}}$ increases at later electrode separation (figure $5 \mathrm{~b}$ ) indicate that water 


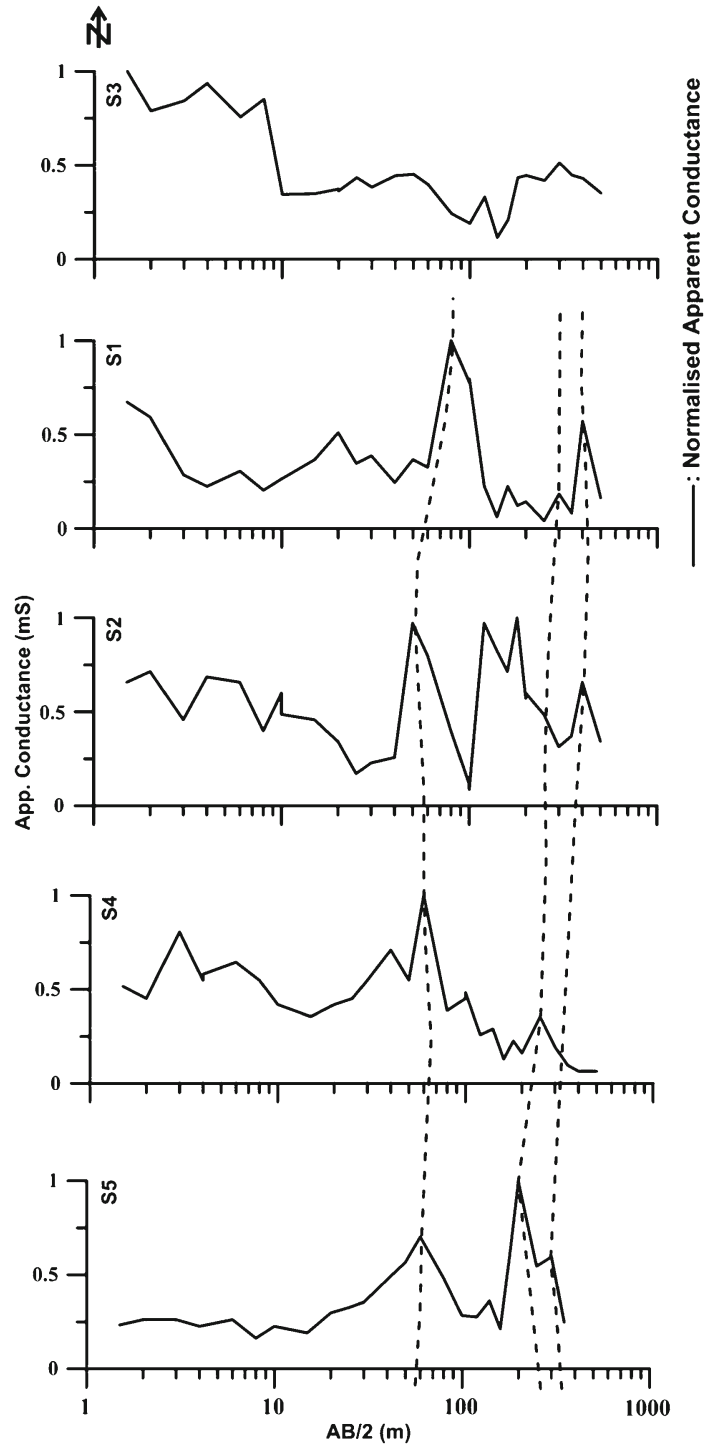

Figure 6. Normalized apparent conductance for five soundings (S1-S5) by their corresponding maximum value (Raghunathpur). saturated layer may be present in the form of saturated mica schist in the basement rock. This location is the best to drill amongst five surveyed locations. Though apparent resistivity data do not suggest the presence of saturated layer once the hard rock will encounter at depth but higher $C_{\mathrm{A}}$ suggest the possibility of getting such a layer. Drilling has been carried out at location S5 and it was successful in getting good amount of groundwater.

\subsection{Raghunathpur (West Bengal)}

The present location falls within the Purulia district of West Bengal. The area is a part of South Purulia Shear Zone which is well known for mineral exploration and highly complex subsurface structure (figure 1d). Here, the resistivity of the subsurface lithology increases with depth and are highly dipping. Due to this, we cannot actually interpret the subsurface structure using conventional resistivity sounding data. $C_{\mathrm{A}}$ helps us to interpret the sounding data in such geologically complex areas. Also, from $C_{\mathrm{A}}$ of five sounding (figure 6 ), we can interpret that there is a linear trend of $C_{\mathrm{A}}$ throughout the area at a deeper depth (current electrode spacing 250-400 m, AB/2). It is interesting to note that the spacing between the sounding locations are about $1-3 \mathrm{~km}$ apart and this shows that how $C_{\mathrm{A}}$ can be used effectively in delineating the conductive zones or subsurface lithological contacts. Table 3 presents the interpreted resistivity and thicknesses of various layers.

\subsubsection{Sounding 1 (S1)}

A 7-layer model (figure 7a) is interpreted on the basis of $C_{\mathrm{A}}$ (figure $7 \mathrm{~b}$ ) in sounding $\mathrm{S} 1$. The

Table 3. Interpreted model parameters for five soundings (S1-S5) from Raghunathpur region.

\begin{tabular}{lccccc}
\hline Parameters & $\mathrm{S} 1$ & $\mathrm{~S} 2$ & $\mathrm{~S} 3$ & $\mathrm{~S} 4$ & $\mathrm{~S} 5$ \\
\hline$\rho_{1}(\Omega \mathrm{m})$ & 131.3 & 169.1 & 12.8 & 680.1 & 252.2 \\
$\rho_{2}(\Omega \mathrm{m})$ & 22.1 & 50.3 & 15.9 & 92.0 & 176.0 \\
$\rho_{3}(\Omega \mathrm{m})$ & 9854 & 387.5 & 150.2 & 167.1 & 484.0 \\
$\rho_{4}(\Omega \mathrm{m})$ & 198.0 & 846.2 & 97382 & 99756 & 2622 \\
$\rho_{5}(\Omega \mathrm{m})$ & 94216 & 10116 & 858.8 & 169.5 & 95720 \\
$\rho_{6}(\Omega \mathrm{m})$ & 795.6 & 936.0 & 99022 & - & 157.0 \\
$\rho_{7}(\Omega \mathrm{m})$ & 99772 & 74155 & - & - & - \\
$\mathrm{h}_{1}(\mathrm{~m})$ & 5.1 & 1.2 & 1.2 & 1.5 & 0.7 \\
$\mathrm{~h}_{2}(\mathrm{~m})$ & 2.3 & 4.3 & 8.8 & 4.2 & 5.9 \\
$\mathrm{~h}_{3}(\mathrm{~m})$ & 74.8 & 9.2 & 28.9 & 5.3 & 24.9 \\
$\mathrm{~h}_{4}(\mathrm{~m})$ & 1.0 & 33.1 & 99.7 & 198.0 & 95.4 \\
$\mathrm{~h}_{5}(\mathrm{~m})$ & 99.7 & 61.8 & 10.1 & - & 87.4 \\
$\mathrm{~h}_{6}(\mathrm{~m})$ & 10.0 & 7.9 & - & - & - \\
Misfit error & $6.8 \times 10^{-3}$ & $1.3 \times 10^{-2}$ & $2.2 \times 10^{-3}$ & $1.2 \times 10^{-3}$ & $3.4 \times 10^{-4}$ \\
\hline
\end{tabular}



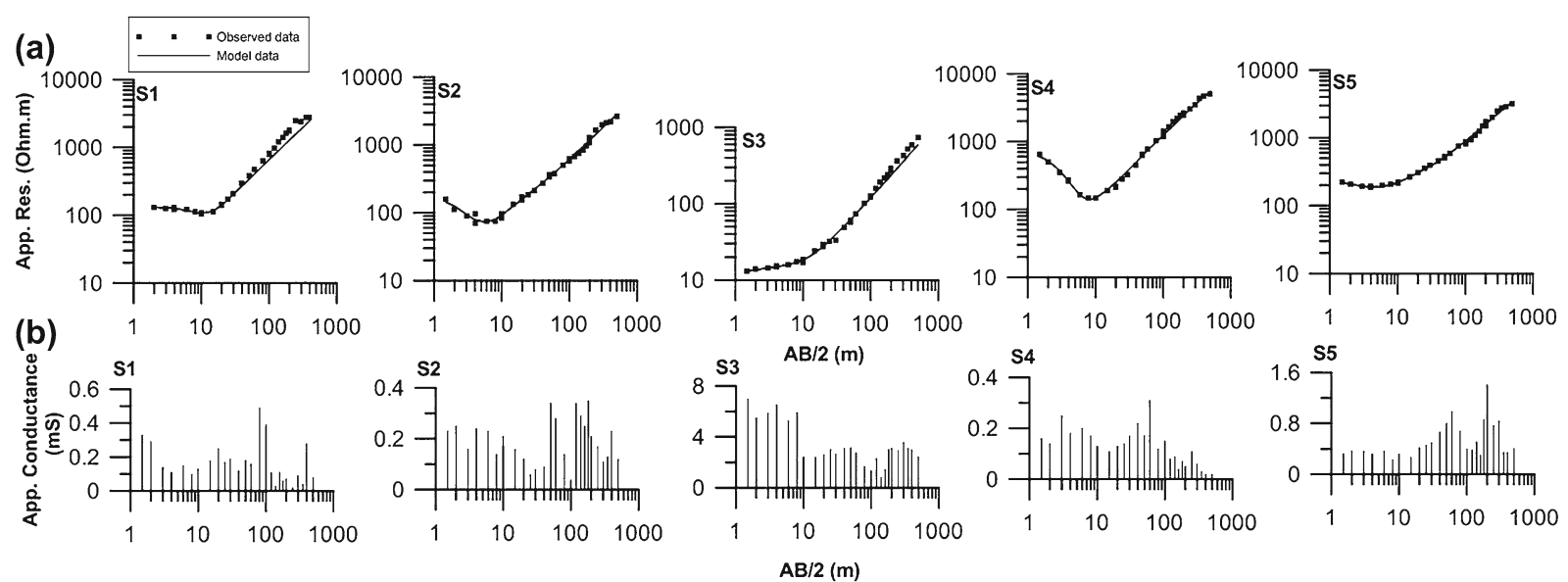

Figure 7. Interpretation of soundings (S1-S5) and variation of apparent conductance with current electrode separations (Raghunathpur).

interpreted model could not match very well with the observed data as the slope of sounding curve is more than $45^{\circ}$. Interpreted model suggests a thick highly resistive layer $(\sim 175 \mathrm{~m})$. The first layer is top dry soil whose resistivity and thickness are interpreted as $131 \Omega \mathrm{m}$ and $5 \mathrm{~m}$, respectively. This is followed by a $2 \mathrm{~m}$ layer of resistivity $22 \Omega \mathrm{m}$. This is also near-surface soil whose resistivity has slightly decreased due to near-surface moisture. Third layer is $74 \mathrm{~m}$ thick and has high resistivity $(9800 \Omega \mathrm{m})$. It is interpreted as massive granite gneiss. Below the massive granite gneiss layer, a conducting layer of resistivity $198 \Omega \mathrm{m}$ can be seen with $1 \mathrm{~m}$ thickness and followed by a highly resistive layer $(94,000 \Omega \mathrm{m})$ with thickness of $99 \mathrm{~m}$. This layer is also interpreted as massive granite gneiss. Sixth layer is a conducting layer of resistivity $795 \Omega \mathrm{m}$ with thickness of $10 \mathrm{~m}$ and is again followed by a highly resistive layer $(99,000 \Omega \mathrm{m})$. This sixth conducting layer is clearly seen in the $C_{\mathrm{A}}$ patterns (figure $7 \mathrm{~b}$ ) and possibly uranium mineralization is present at that particular layer. This conducting layer could not have been detected by the conventional interpretation of apparent resistivity data. Due to deviation from the layered assumption the thicknesses cannot be interpreted accurately below the massive granite. However, presence of conducting layer cannot be ruled out below this which has been detected from $C_{\mathrm{A}}$.

\subsubsection{Sounding 2 (S2)}

The interpretation of sounding data (S2) also suggests a 7-layer model (figure 7a). The interpreted model matches very well with the observed data. Interpreted data suggest a high resistive layer $(\sim 62 \mathrm{~m})$ which is also seen in S1. Below this resistive layer, there is a prominent conducting layer which can be seen from the current flow pattern and sounding data but the actual thickness is still unclear. The first layer is top dry soil whose resistivity and thickness are interpreted as $169 \Omega \mathrm{m}$ and $1.18 \mathrm{~m}$, respectively. This is followed by a $4 \mathrm{~m}$ layer of resistivity $50 \Omega \mathrm{m}$. This is also near-surface soil whose resistivity has slightly decreased due to near-surface moisture. Third layer is $9 \mathrm{~m}$ thick and has resistivity $387 \Omega \mathrm{m}$. This layer is weathered schist mixed with moist soil. Weathered schist layer followed a layer of resistivity $846 \Omega \mathrm{m}$ and thickness $33 \mathrm{~m}$. This fourth layer is compact schist. Fifth layer is $61 \mathrm{~m}$ thick and has high resistivity $(10,000 \Omega \mathrm{m})$. It is interpreted as massive granite gneiss. Below the massive granite layer, a conducting layer can be seen and its resistivity is interpreted as $936 \Omega \mathrm{m}$ followed by a highly resistive layer $(74,000 \Omega \mathrm{m})$. The thickness of this conducting layer is interpreted as $8 \mathrm{~m}$. This conducting layer is clearly seen in the $C_{\mathrm{A}}$ patterns (figure $7 \mathrm{~b}$ ) and possibly uranium mineralization is present at that particular layer.

\subsubsection{Sounding 3 (S3)}

The interpretation of sounding data (S3) suggests a 6-layer model (figure 7a), although the subsurface layers in that area are dipping towards north. This sounding also shows a high resistive layer $(\sim 100 \mathrm{~m})$. Below this layer there is a conductor which can be delineated from the current flow pattern but the thickness is still uncertain. The first layer is top dry soil whose resistivity and thickness are interpreted as $13 \Omega \mathrm{m}$ and $1.18 \mathrm{~m}$, respectively. This is followed by an $8.77 \mathrm{~m}$ thick layer of resistivity $15 \Omega \mathrm{m}$. This is also near-surface soil whose resistivity has slightly decreased due to near-surface moisture. Third layer is $29 \mathrm{~m}$ thick and has resistivity $150 \Omega \mathrm{m}$. This layer is weathered schist mixed with moist soil. Weathered schist layer is followed by fourth layer which is massive granite gneiss. Resistivity of this layer is very 
high $(97,000 \Omega \mathrm{m})$ and thickness $99 \mathrm{~m}$. Below the massive granite gneiss layer a conducting layer can be seen and its resistivity is interpreted as $858 \Omega \mathrm{m}$ followed by a highly resistive layer $(99,000 \Omega \mathrm{m})$. The thickness of this conducting layer is interpreted as $10 \mathrm{~m} . C_{\mathrm{A}}$ at this location is completely different and uncorrelated with other $C_{\mathrm{A}}$ at sounding locations (figure $7 \mathrm{~b}$ ).

\subsubsection{Sounding 4 (S4)}

The interpretation of sounding data (S4) suggests a 5-layer model (figure 7a). The first layer is top dry soil whose resistivity and thickness are interpreted as $680 \Omega \mathrm{m}$ and $1.50 \mathrm{~m}$, respectively. This is followed by a $4.18 \mathrm{~m}$ thick layer of resistivity $92 \Omega \mathrm{m}$. This is also near-surface soil whose resistivity has slightly decreased due to near-surface moisture. Third layer is $5.28 \mathrm{~m}$ thick and has resistivity $167 \Omega \mathrm{m}$. This layer is weathered schist mixed with moist soil. Weathered schist layer is followed by fourth layer which is massive granite gneiss. Its resistivity is very high $(99,000 \Omega \mathrm{m})$ and thickness $198 \mathrm{~m}$. Below the massive granite gneiss layer a conducting layer can be seen and its resistivity is interpreted as $169 \Omega \mathrm{m}$. Since this is the last layer, its thickness cannot be interpreted. This conducting layer is clearly seen in the $C_{\mathrm{A}}$ patterns (figure $7 \mathrm{~b}$ ) and possibly uranium mineralization is present at that particular layer.

\subsubsection{Sounding 5 (S5)}

Interpreted model parameter for S5 suggests a 6-layer model (figure 7a). The first layer is top dry loose soil whose resistivity and thickness are interpreted as $252 \Omega \mathrm{m}$ and $0.73 \mathrm{~m}$, respectively. This is followed by a $5.97 \mathrm{~m}$ thick layer of resistivity $176 \Omega \mathrm{m}$. This is also near-surface soil whose resistivity has slightly decreased due to near-surface moisture. Third layer is about $25 \mathrm{~m}$ thick and has resistivity $484 \Omega \mathrm{m}$. This layer is weathered schist. Weathered granite layer followed a layer of resistivity $2622 \Omega \mathrm{m}$ and thickness $95 \mathrm{~m}$. This fourth layer is compact schist. Fifth layer is $87 \mathrm{~m}$ thick and has very high resistivity $(95,000 \Omega \mathrm{m})$. It is interpreted as massive granite gneiss. Below the massive granite gneiss layer, a conducting layer can be seen and its resistivity is interpreted as $157 \Omega \mathrm{m}$. Since this is the last layer, its thickness cannot be interpreted. This conducting layer is clearly seen in the $C_{\mathrm{A}}$ patterns (figure $7 \mathrm{~b}$ ) and possibly uranium mineralization is present at that particular layer.

\section{Discussions}

Resistivity profiling and sounding are the commonly used geophysical techniques for delineation of groundwater bearing thin structures in hard rock area and subsurface mineral exploration in different geological terrains. In spite of the fact that electrical resistivity of subsurface structures changes significantly in the presence of groundwater and mineral, detection of thin conducting zones in hard rock areas using resistivity method is a challenging task. Thin conducting structures buried at large depth (fractures filled with groundwater and mineral aggregate) are not reflected in the resistivity sounding data because measured apparent resistivity data is the bulk resistivity of complex subsurface structures. Further, in a continuously increasing or decreasing trend of apparent resistivity with current electrode separation (Atype and Q-type structures), intermediate layer is suppressed in the data. There should be some approach in electrical resistivity measurement to solve these two problems. Attempt is made to address these two problems and their possible solution in this study. Measurement of apparent conductance between current electrodes that governs the magnitude of current flow could be the possible solution for the above-mentioned problems. However, for such measurement, monitoring of ground conditions near current electrode is required. This is to understand whether increase or decrease in current flow is caused by local condition near current electrodes or it is resulting from change in conductivity at depth. Therefore, uniformity in the ground condition near current electrode should be maintained by putting the same amount of water at each current electrode location.

Apparent conductance $\left(C_{\mathrm{A}}\right)$ and resistivity sounding have been studied in different geological terrains for groundwater and mineral exploration. The utility of $C_{\mathrm{A}}$ for depicting the possible groundwater in fractured rocks and uranium bearing structure is validated. The approach is also utilized in mapping the subsurface lithological contacts where the resistivity of the subsurface lithology increases with depth. This method can also depict the interface of saline and fresh water in coastal area. The method can be effectively used in the countries (Middle East and Africa) where there is paucity of groundwater availability in the shallow and deeper aquifers. The $C_{\mathrm{A}}$ can also help in monitoring of subsurface reservoir using a vast current electrode spread in 3-D environment.

\section{Conclusions}

Apparent conductance between two current electrodes is studied simultaneously with conventional Schlumberger resistivity sounding to detect thin conducting layer at depth (associated with groundwater and mineralized zone). A sharp increase in 
apparent conductance for a particular current electrode separation indicates the presence of thin conducting layer at depth. It has been observed that $C_{\mathrm{A}}$ increases significantly whenever groundwater bearing fractures and thin mineralized zones are encountered in the subsurface. The approach has been used in different hard rock areas for successful prediction of groundwater layers and mineral exploration at depth where conventional resistivity sounding failed to detect such layers. This method could be utilized to depict the lithological contacts at depth and as well as solve the problem of suppression in D.C. resistivity survey.

\section{Acknowledgements}

The authors would like to express their sincere thanks to Prof. Nibir Mandal (Associate Editor) and anonymous reviewers for the comments and suggestions that have improved the manuscript. Various studies presented in the paper are parts of consultancy projects. Funding agencies Chandrashekar College, Paschim Midnapore (Silda), Indian Oil Corporation Ltd. (Baharagora) and Public Health and Engineering (PHE) Department (Sankrail), Paschim Midnapore are acknowledged for their financial support and various drilling information such as litholog as well as yield of drilled boreholes.

\section{Appendix 1}

\section{Theoretical formulations of horizontal current density}

Over a multilayered earth, the general solution for potential in the $i$ th layer $\left(V_{i}\right)$ at any point $(r, z)$ due to a point current source $(I)$ placed on the earth surface is given by Bhattacharya and Patra (1968).

$$
\begin{aligned}
V_{i}(r, z)= & \frac{I \rho_{1}}{2 \pi} \frac{1}{\left(r^{2}+z^{2}\right)^{1 / 2}}+\int_{0}^{\infty}\left\{A_{i}(m) e^{-m z}\right. \\
& \left.+B_{i}(m) e^{m z}\right\} J_{0}(m r) d m .
\end{aligned}
$$

The coefficients $A_{i}$ and $B_{i}$ can be determined from the boundary conditions. The boundary conditions to be satisfied at any boundary are:

$$
V_{i}=V_{i+1}
$$

and

$$
\frac{1}{\rho_{i}} \frac{\partial V_{i}}{\partial z}=\frac{1}{\rho_{i+1}} \frac{\partial V_{i+1}}{\partial z} \quad \text { at } z=H_{i}
$$

$H_{i}$ is the depth of the $i$ th interface from surface and $\rho_{i}$ is the resistivity of the $i$ th layer. It has been shown by Bhattacharya and Patra (1968) that coefficient $A_{1}=B_{1}$ and $B_{n}=0$. There are equal number of unknowns and equations hence all the coefficients $A_{i}$ and $B_{i}$ can be solved uniquely for $n$-layer structure.

For a three-layer case, following four equations can be written for two interfaces.

$$
\begin{gathered}
A_{1}\left(e^{-m H_{1}}+e^{m H_{1}}\right)-A_{2} e^{-m H_{1}}-B_{2} e^{m H_{1}}=0 \\
A_{1} \rho_{2}\left(-e^{-m H_{1}}+e^{m H_{1}}\right)+A_{2} \rho_{1} e^{-m H_{1}} \\
-B_{2} \rho_{1} e^{m H_{1}}-q\left(\rho_{2}-\rho_{1}\right) e^{-m H_{1}}=0 \\
A_{2} e^{-m H_{2}}+B_{2} e^{m H_{2}}-A_{3} e^{-m H_{2}}=0 \\
-A_{2} \rho_{3} e^{-m H_{2}}+B_{2} \rho_{3} e^{m H_{2}}+A_{3} \rho_{2} e^{-m H_{2}} \\
-q\left(\rho_{3}-\rho_{2}\right) e^{-m H_{2}}=0
\end{gathered}
$$

In equations (5) and (7), $q$ is given by the relation $q=\left(\rho_{1} I / 2 \pi\right)$.

Since D.C. resistivity method deals with potential measurement at the earth's surface, therefore, solution of coefficient $A_{1}$ is sufficient. Solution for potential on the earth surface can be written in terms of resistivity transform and apparent resistivity can be computed using digital linear filtering (Ghosh 1971; Koefoed 1979). This can also be found in standard text book dealing with electrical methods. However, computation of potential at any point inside the earth and subsequent derivation of current density in various layers requires the solution of all coefficients $\left(A_{i}\right.$ and $\left.B_{i}\right)$.

For, a 3-layer case, solution for the four coefficients is derived by solving equations (4) to (7).

$$
\begin{aligned}
A_{1} & =q \frac{K_{12} g^{p_{1}}+K_{23} g^{p_{2}}}{1-K_{12} g^{p_{1}}-K_{23} g^{p_{2}}+K_{12} K_{23} g^{p_{2}-p_{1}}} \\
A_{2} & =q \frac{K_{12} g^{p_{1}}+K_{23} g^{p_{2}}-K_{12} K_{23} g^{p_{2}-p_{1}}+K_{12}}{1-K_{12} g^{p_{1}}-K_{23} g^{p_{2}}+K_{12} K_{23} g^{p_{2}-p_{1}}} \\
B_{2} & =q \frac{K_{23}\left(K_{12}+1\right) g^{p_{2}}}{1-K_{12} g^{p_{1}}-K_{23} g^{p_{2}}+K_{12} K_{23} g^{p_{2}-p_{1}}}
\end{aligned}
$$

$$
A_{3}=q \frac{K_{12} g^{p_{1}}+K_{23} g^{p_{2}}-K_{12} K_{23} g^{p_{2}-p_{1}}+K_{12}+K_{23}+K_{12} K_{23}}{1-K_{12} g^{p_{1}}-K_{23} g^{p_{2}}+K_{12} K_{23} g^{p_{2}-p_{1}}}
$$


In equations (8-11), $K_{i j}=\left(\rho_{j}-\rho_{i}\right) /\left(\rho_{j}+\rho_{i}\right)$, $e^{-2 m H_{0}}=g$ and $p_{1}, p_{2}$ are whole numbers such that $p_{1}=H_{1} / H_{0}, p_{2}=H_{2} / H_{0}\left(H_{0}\right.$ has some fixed value). Since $p_{1}$ and $p_{2}$ are whole numbers, $A_{1}$ is rational function of $g$, therefore, we can write:

$$
A_{1}=q\left(b_{1} g+b_{2} g^{2}+b_{3} g^{3}+\cdots\right)=q \sum_{n=1}^{\infty} b_{n} g^{n}
$$

Since, coefficients of any order of $g$ must be identical in both expressions (equations 8 and 12), the coefficients $b_{n}$ can be obtained by equating the coefficients of $g^{n}$ in the above two equations. Similarly $A_{2}, B_{2}$ and $A_{3}$ are obtained. Let

$$
\begin{aligned}
& A_{2}=q \sum_{n=0}^{\infty} c_{n} g^{n}, \\
& B_{2}=q \sum_{n=1}^{\infty} d_{n} g^{n}, \\
& A_{3}=q \sum_{n=0}^{\infty} e_{n} g^{n} .
\end{aligned}
$$

Thus the potential at any point in different layers, due to a single electrode on the surface can be written as:

$$
\begin{aligned}
V_{1}= & \frac{I \rho_{1}}{2 \pi}\left[\frac{1}{\sqrt{r^{2}+z^{2}}}+\sum_{n=1}^{\infty} \frac{b_{n}}{\sqrt{r^{2}+\left(2 n H_{0}+z\right)^{2}}}\right. \\
& \left.+\sum_{n=1}^{\infty} \frac{b_{n}}{\sqrt{r^{2}+\left(2 n H_{0}-z\right)^{2}}}\right]
\end{aligned}
$$

$$
\begin{aligned}
V_{2}= & \frac{I \rho_{1}}{2 \pi}\left[\frac{1}{\sqrt{r^{2}+z^{2}}}+\sum_{n=0}^{\infty} \frac{c_{n}}{\sqrt{r^{2}+\left(2 n H_{0}+z\right)^{2}}}\right. \\
& \left.+\sum_{n=1}^{\infty} \frac{d_{n}}{\sqrt{r^{2}+\left(2 n H_{0}-z\right)^{2}}}\right]
\end{aligned}
$$

$$
V_{3}=\frac{I \rho_{1}}{2 \pi}\left[\frac{1}{\sqrt{r^{2}+z^{2}}}+\sum_{n=0}^{\infty} \frac{e_{n}}{\sqrt{r^{2}+\left(2 n H_{0}+z\right)^{2}}}\right]
$$

The potential at any point in different layers, due to two electrodes placed at a distance $L$ apart on the surface can be written as:

$$
\begin{gathered}
V_{1}=\frac{I \rho_{1}}{2 \pi}\left[\begin{array}{l}
\frac{1}{\sqrt{r_{1}^{2}+z^{2}}}+\sum_{n=1}^{\infty} \frac{b_{n}}{\sqrt{r_{1}^{2}+\left(2 n H_{0}+z\right)^{2}}}+\sum_{n=1}^{\infty} \frac{b_{n}}{\sqrt{r_{1}^{2}+\left(2 n H_{0}-z\right)^{2}}}-\frac{1}{\sqrt{r_{2}^{2}+z^{2}}} \\
-\sum_{n=1}^{\infty} \frac{b_{n}}{\sqrt{r_{2}^{2}+\left(2 n H_{0}+z\right)^{2}}}-\sum_{n=1}^{\infty} \frac{b_{n}}{\sqrt{r_{2}^{2}+\left(2 n H_{0}-z\right)^{2}}}
\end{array}\right] \\
V_{2}=\frac{I \rho_{1}}{2 \pi}\left[\begin{array}{l}
\frac{1}{\sqrt{r_{1}^{2}+z^{2}}}+\sum_{n=0}^{\infty} \frac{c_{n}}{\sqrt{r_{1}^{2}+\left(2 n H_{0}+z\right)^{2}}}+\sum_{n=1}^{\infty} \frac{d_{n}}{\sqrt{r_{1}^{2}+\left(2 n H_{0}-z\right)^{2}}}-\frac{1}{\sqrt{r_{2}^{2}+z^{2}}} \\
-\sum_{n=0}^{\infty} \frac{c_{n}}{\sqrt{r_{2}^{2}+\left(2 n H_{0}+z\right)^{2}}}-\sum_{n=1}^{\infty} \frac{d_{n}}{\sqrt{r_{2}^{2}+\left(2 n H_{0}-z\right)^{2}}}
\end{array}\right]
\end{gathered}
$$

$$
\begin{aligned}
V_{3}= & \frac{I \rho_{1}}{2 \pi}\left[\frac{1}{\sqrt{r_{1}^{2}+z^{2}}}+\sum_{n=0}^{\infty} \frac{e_{n}}{\sqrt{r_{1}^{2}+\left(2 n H_{0}+z\right)^{2}}}\right. \\
& \left.-\frac{1}{\sqrt{r_{2}^{2}+z^{2}}}-\sum_{n=0}^{\infty} \frac{e_{n}}{\sqrt{r_{2}^{2}+\left(2 n H_{0}+z\right)^{2}}}\right]
\end{aligned}
$$

where $r_{1}$ and $r_{2}$ are distances from the first and second electrodes, respectively.

The horizontal current density $j_{x}$ at a point is given by:

$$
j_{x}=-\frac{1}{\rho} \frac{\partial V}{\partial x} .
$$

Thus the horizontal current densities in different layers at a depth $z$ and $L / 2$ units from each electrode can be obtained as:

$$
\begin{aligned}
j_{x}= & \frac{I}{2 \pi}\left[\frac{L}{\left(\frac{L^{2}}{4}+z^{2}\right)^{3 / 2}}+\sum_{n=1}^{\infty} \frac{b_{n} L}{\left(\frac{L^{2}}{4}+\left(2 n H_{0}+z\right)^{2}\right)^{3 / 2}}\right. \\
& \left.+\sum_{n=1}^{\infty} \frac{b_{n} L}{\left(\frac{L^{2}}{4}+\left(2 n H_{0}-z\right)^{2}\right)^{3 / 2}}\right] \quad \text { for } z \leq H_{1}
\end{aligned}
$$




$$
\begin{array}{rlr}
j_{x}= & \frac{I \rho_{1}}{2 \pi \rho_{2}}\left[\frac{L}{\left(\frac{L^{2}}{4}+z^{2}\right)^{3 / 2}}+\sum_{n=0}^{\infty} \frac{c_{n} L}{\left(\frac{L^{2}}{4}+\left(2 n H_{0}+z\right)^{2}\right)^{3 / 2}} \quad j_{x}=\frac{I \rho_{1}}{2 \pi \rho_{3}}\left[\frac{L}{\left(\frac{L^{2}}{4}+z^{2}\right)^{3 / 2}}\right.\right. \\
& \left.+\sum_{n=1}^{\infty} \frac{d_{n} L}{\left(\frac{L^{2}}{4}+\left(2 n H_{0}-z\right)^{2}\right)^{3 / 2}}\right] \quad \text { for } H_{1}<z \leq H_{2} & \left.+\sum_{n=0}^{\infty} \frac{e_{n} L}{\left(\frac{L^{2}}{4}+\left(2 n H_{0}+z\right)^{2}\right)^{3 / 2}}\right] \quad \text { for } z>H_{2} .
\end{array}
$$
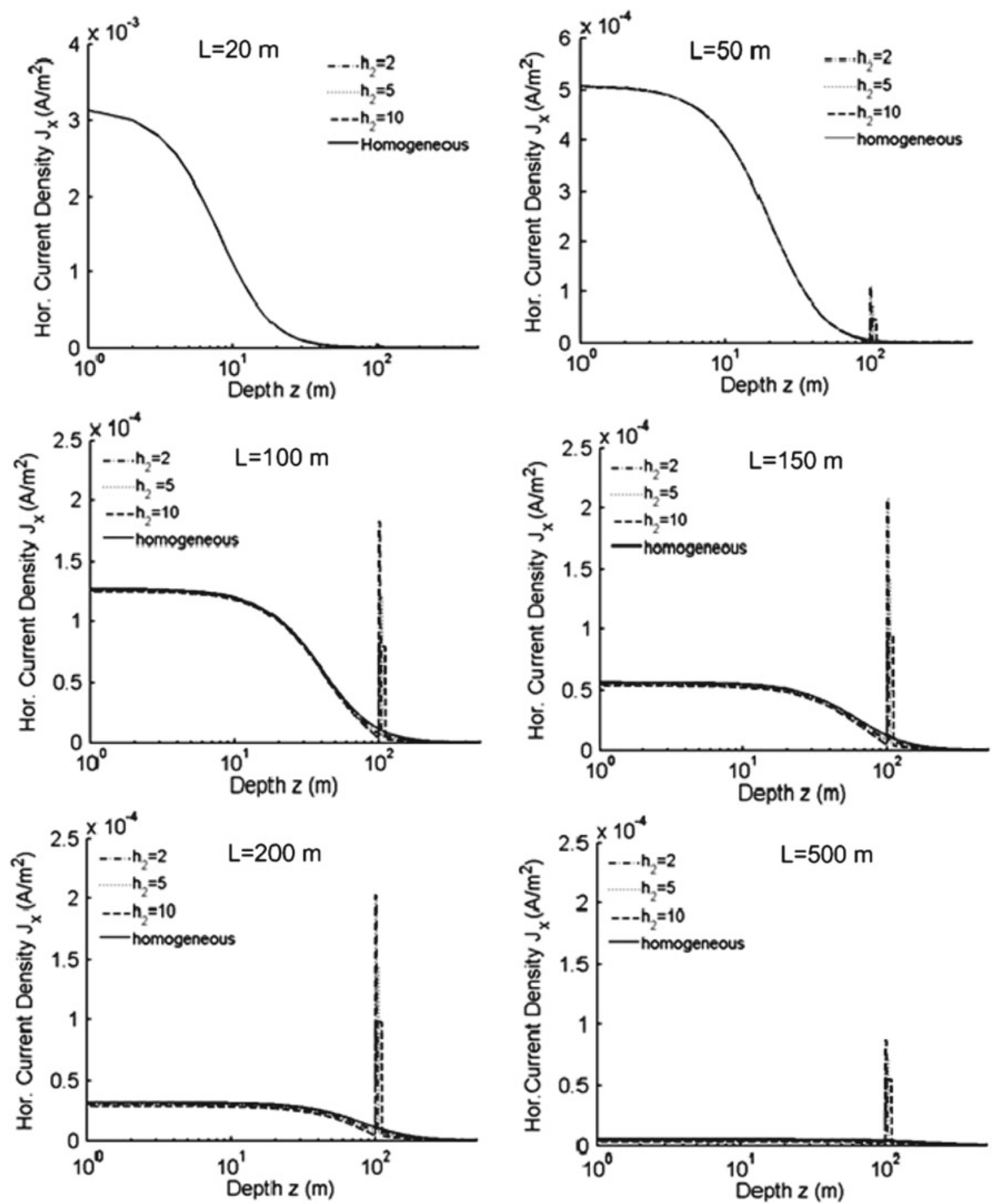

Figure A1. Variation of horizontal current density with depth for different current electrode separation. 
Current density over homogeneous half-space is given by the first term of equation (23) and it is independent on the resistivity of the medium (Telford et al. 1990). Current density computed over 3-layered earth will be compared with current density in homogeneous half-space to demonstrate the increase in current flow when a conducting layer will encounter at depth. A three-layer model is depicted by putting a $10 \Omega \mathrm{m}$ layer at $100 \mathrm{~m}$ depth in a $250 \Omega \mathrm{m}$ homogeneous half-space. Hence the model resistivities are 250, 10, $250 \Omega \mathrm{m}$ and thickness of top layer $100 \mathrm{~m}$ with variable second layer thickness 2, 5 and $10 \mathrm{~m}$.

Variation of current density with depths (0$200 \mathrm{~m}$ ) for different current electrode separations $(20,50,100,150,200$, and $500 \mathrm{~m})$ over 3-layer model mentioned above are presented in figure A1. Current density is higher at shallower depth for smaller current electrode separations and then gradually decreases with the increase of current electrode separation. Current density in the intermediate conducting layer is very small at smaller electrode separation ( $L=20 \mathrm{~m}$ in figure A1) and it increases gradually with the increase in current electrode separation. It becomes maximum at a given current electrode separation and then decreases with the increase in the current electrode separation. Variation of current density for different thickness of the conducting layer is also shown in figure A1. It is observed that the magnitude of current density is more for a thin layer $(2 \mathrm{~m})$ compared to a thick layer $(10 \mathrm{~m})$.

In this section, mathematically it has been shown that current density will not be always maximum at the surface. Instead it will be greater at depth when a conducting layer encounter at depth. In such situation, current flow will increase for larger current electrode separations.

\section{References}

Apostolopoulos G 2008 Combined Schlumberger and dipole-dipole array for hydrogeologic applications; Geophysics 73 189-195.

Auken E, Louise P, Christensen Niels B and Sørensen K 2006 A survey of current trends in near-surface electrical and electromagnetic methods; Geophysics $\mathbf{7 1}$ 249-260.
Bernard J and Valla P 1991 Groundwater exploration in fissured media with electrical and VLF methods; Geoexploration 27 81-91.

Bhattacharya P K and Patra H P 1968 Direct current geoelectric sounding; In: Methods in Geochem. Geophys., Elsevier Science Ltd.

Blome M, Maurer H and Greenhalgh S 2011 Geoelectric experimental design - Efficient acquisition and exploitation of complete pole-bipole data sets; Geophysics $\mathbf{7 6}$ F15-F26.

Dickinson J E, Pool D R, Groom R W and Davis L J 2010 Inference of lithologic distributions in an alluvial aquifer using airborne transient electromagnetic surveys; Geophysics 75 WA149-WA161.

Furman A, Ferré A, Ty P and Heath G L 2007 Spatial focusing of electrical resistivity surveys considering geologic and hydrologic layering; Geophysics 72 65-73.

Ghosh D P 1971 The application of linear filter theory to the direct interpretation of geoelectrical resistivity sounding measurements; Geophys. Prospecting 19 176-180.

Goldman M and Neubauer F M 1994 Groundwater exploration using integrated geophysical techniques; Surv. Geophys. 15 331-361.

Koefoed O 1979 Geosounding Principles 1: Resistivity Sounding Measurements; Elsevier, Amsterdam.

Legault J M, Carriere D and Petrie L 2008 Synthetic model testing and distributed acquisition dc resistivity results over an unconformity uranium target from the Athabasca Basin, northern Saskatchewan; The Leading Edge $\mathbf{2 7}$ 46-51.

Maurer H, Curtis A and Boerner D E 2010 Recent advances in optimized geophysical survey design; Geophysics $\mathbf{7 5}$ 75A177-75A194.

Monteiro Santos F A, Sultan S A, Represas P and Sorady A L El 2006 Joint inversion of gravity and geoelectrical data for groundwater and structural investigation: Application to the northwestern part of Sinai, Egypt; Geophys. J. Int. 165 705-718.

Nimeck G and Koach R 2008 A progressive geophysical exploration strategy at the Shea Creek uranium deposit; The Leading Edge 27 52-63.

Sharma S P and Baranwal V C 2005 Delineation of groundwater-bearing fracture zones in a hard rock area integrating very low frequency electromagnetic and resistivity data; J. Appl. Geophys. 57 155-166.

Sharma S P and Kaikkonen P 1999 Appraisal of equivalence and suppression problems in 1-D EM and DC measurements using global optimization and joint inversion; Geophys. Prospecting 47 219-249.

Sharma S P and Verma S K 2011 Solutions of the inherent problem of the equivalence in direct current resistivity and electromagnetic methods through global optimization and joint inversion by successive refinement of model space; Geophys. Prospecting 59 760-776.

Telford W M, Geldart L P and Sheriff R E 1990 Applied Geophysics; 2nd edn, Cambridge University Press.

Van Overmeeren R A 1989 Aquifer boundaries explored by geoelectrical measurements in the coastal plain of Yemen: A case of equivalence; Geophysics 54 38-48. 